\title{
On the importance of including vegetation dynamics in Budyko's hydrological model
}

\author{
R. J. Donohue ${ }^{1,2}$, M. L. Roderick ${ }^{1}$, and T. R. McVicar $^{2}$ \\ ${ }^{1}$ Environmental Biology Group, Research School of Biological Sciences, Australian National University, Canberra, ACT \\ 0200, Australia \\ ${ }^{2}$ CSIRO Land and Water and eWater Cooperative Research Centre, GPO Box 1666, Canberra, ACT 2601, Australia
}

Received: 20 January 2006 - Published in Hydrol. Earth Syst. Sci. Discuss.: 12 July 2006

Revised: 10 October 2006 - Accepted: 5 March 2007 - Published: 13 March 2007

\begin{abstract}
The Budyko curve describes the patterns observed between between climate, evapotranspiration and run-off and has proven to be a useful model for predicting catchment energy and water balances. In this paper we review the Budyko curve's underlying framework and, based on the literature, present an argument for why it is important to include vegetation dynamics into the framework for some purposes. The Budyko framework assumes catchments are at steady-state and are driven by the macro-climate, two conditions dependent on the scales of application, such that the framework's reliability is greatest when applied using long-term averages $\left(\gg 1\right.$ year) and to large catchments $\left(>10000 \mathrm{~km}^{2}\right)$. At these scales previous experience has shown that the hydrological role of vegetation does not need to be explicitly considered within the framework. By demonstrating how dynamics in the leaf area, photosynthetic capacity and rooting depth of vegetation affect not only annual and seasonal vegetation water use, but also steady-state conditions, we argue that it is necessary to explicitly include vegetation dynamics into the Budyko framework before it is applied at small scales. Such adaptations would extend the framework not only to applications at small timescales and/or small catchments but to operational activities relating to vegetation and water management.
\end{abstract}

\section{Introduction}

Efforts to better understand the components of the catchment water balance have traditionally been the realm of the hydrological community. Investigations have used models predominantly based on physical processes and applications have generally remained in the same arena. Very few catchment-scale hydrological models incorporate vegetation

Correspondence to: R. J. Donohue

(randall.donohue@csiro.au) or, in those that do, it is often included generically or in abstract terms that are difficult to measure across space and through time. This is beginning to change with the recognition by the hydrological community that biological processes play a key role in the catchment water balance (RodriguezIturbe and Porporato, 2005; Montaldo et al., 2004). One key feature of this role is that transpiration, a major component of the catchment water balance, and biological productivity are intimately coupled (Berry et al., 2005). The fields of hydrology and ecology will benefit from a more integrated understanding of catchment behaviour. This is the central challenge of ecohydrology.

In order to characterise the components of catchment water balances, Budyko (1974) developed what is now one of the most enduring frameworks that links climate to catchment run-off and evapotranspiration. It is simple to interpret and plainly links basic physical principles governing the catchment water balance. The resulting relationship, widely known as the "Budyko curve", partitions average precipitation into average run-off and average evapotranspiration. Deviations around this relationship are observed and considerable work has been done to explain these deviations, attributing them to variability and seasonality in climate, to soil characteristics, to vegetation type and to the scales of analyses.

It seems likely that the quantitative integration of measures of key vegetation characteristics might enhance the Budyko framework. If true, then the applicability of the framework might be extended to a variety of land management applications. The purpose of this paper is to review the Budyko framework with particular reference to vegetation and, by highlighting the dynamic role vegetation often plays in catchment behaviour, to argue the importance of including spatially and temporally dynamic measures of vegetation into Budyko's framework. More specifically, this review:

1. explicitly quantifies some of the assumptions inherent in the water balance as formulated by Budyko, particularly

Published by Copernicus GmbH on behalf of the European Geosciences Union. 
those relating to steady-state conditions (Sect. 2);

2. examines the Budyko-related literature focusing on how vegetation processes and dynamics can affect the assumption of steady-state conditions within the framework as well as the components of the water balance itself (Sect. 3);

3. collates information from the literature that demonstrates the magnitude to which vegetation dynamics can affect the water balance and the timescales over which these effects can operate (Sect. 4); and

4. suggests some potential ways forward for investigating how time-series remote sensing may enable vegetation dynamics to be incorporated into the Budyko framework (Sect. 5).

\section{The Budyko framework and curve}

In the middle of last century Budyko $(1958,1974)$ published a framework describing the partitioning of average precipitation into average evapotranspiration and average run-off based on simple physical relationships. This is now known as the "Budyko curve" and is described below.

\subsection{Catchment water and energy balances}

Budyko described the hydrology of a catchment using a supply-demand framework and a simple bucket model where net drainage is assumed to be negligible. The water balance was defined as:

$\frac{d S_{w}}{d t}=P-E-Q$

where $E, P$ and $Q$ are catchment-wide estimates of evapotranspiration, precipitation and run-off fluxes, respectively (in SI units, which will be the units used henceforth, these are all $\left.\mathrm{kg} \mathrm{s}^{-1}\right)$, and $S_{w}(\mathrm{~kg})$ is the soil water storage. A catchment is in steady-state when changes in $S_{w}$ are zero. In reality, $\frac{d S_{w}}{d t}$ is almost continually varying due to fluctuations in $P, Q$ and $E$ and steady-state conditions are typically established in analyses by integrating Eq. (1) over a finite time period $(\tau)$ that is larger than the time-scale of fluctuations in $S_{w}$ :

$\int_{0}^{\tau} \frac{d S_{w}}{d t} d t=\int_{0}^{\tau} P d t-\int_{0}^{\tau} E d t-\int_{0}^{\tau} Q d t$

In finite form we have the catchment mass balance:

$$
\Delta S_{w}=\bar{P} \tau-\bar{E} \tau-\bar{Q} \tau
$$

or

$$
\frac{\Delta S_{w}}{\tau}=\bar{P}-\bar{E}-\bar{Q}
$$

We can convert to the familiar depth units by dividing both sides by the catchment area $\left(A_{c}, \mathrm{~m}^{2}\right)$ and the density of liquid water $\left(\rho_{w}, \mathrm{~kg} \mathrm{~m}^{-3}\right)$ :

$$
\frac{\Delta S_{w}}{\rho_{w} A_{c} \tau}=\frac{\bar{P}-\bar{E}-\bar{Q}}{\rho_{w} A_{c}}
$$

The framework can be further extended by noting that soil water depends on the volume of the bucket $\left(V, \mathrm{~m}^{3}\right)$ and the mass concentration of water in the bucket $\left(\left[S_{w}\right], \mathrm{kg} \mathrm{m}^{-3}\right)$ :

$S_{w}=V\left[S_{w}\right]$

An upper limit to $\left[S_{w}\right]$ is set by the pore space within the soil which is a function of soil texture and structure (Craze and Hamilton, 1991). Soil water can change because of a change in the volume of the bucket or a change in mass concentration within the volume. To the first order we have:

$\Delta S_{W}=\left[S_{w}\right] \Delta V+V \Delta\left[S_{w}\right]$

The volume of the bucket depends on the catchment area and bucket depth $(z, \mathrm{~m})$ :

$V=A_{c} z$

For a given catchment, the area is fixed and the volume of the bucket can only change because of the change in depth $(\Delta z)$. With that, and combining Eqs. (5, 7 and 8):

$$
\frac{1}{\rho_{w}}\left(\left[S_{w}\right] \frac{\Delta z}{\tau}+z \frac{\Delta\left[S_{w}\right]}{\tau}\right)=\frac{\bar{P}-\bar{E}-\bar{Q}}{\rho_{w} A_{c}}
$$

Formulating the water balance in this way allows links to be made (later in Sects. 3 and 4) between vegetation characteristics and the spatial analysis scales, as well as the "flux components" (RHS of Eq. 9, that is, $\bar{Q}$ and $\bar{E}$ ) and the "steady-state components" (LHS of Eq. 9) of the water balance. Even though this seems more complicated than Eq. (1) it has the advantage that it makes all the terms, especially $A_{c}$, $\tau$ and $z$, explicit. Firstly, $A_{c}$ determines the spatial scale of analyses. Budyko only examined catchments with $A_{c}$ well over $1000 \mathrm{~km}^{2}$, partly to minimise the effect of any groundwater flow (i.e. to ensure the validity of the bucket model) as he assumed this to be negligible, and partly to minimise the effect of "local conditions" on $\bar{E}$ (see Sect. 2.2). Secondly, $\tau$ determines the timescale of analyses. In developing his framework, Budyko assumed catchments were at steadystate (i.e. LHS of Eq. $(9) \rightarrow 0$ ). Budyko therefore a priori selected a value of $\tau$ to ensure that the steady-state assumptions would be reasonable. In doing that, Budyko found that $\Delta S_{w}$ can be as large as $\bar{E}$ or $\bar{Q}$ over a single year, and so set $\tau$ to be much greater than 1 year by using long-term averages. Lastly, $z$ controls total possible $S_{w}$. However, under the assumption that groundwater flow is negligible, water loss from the bucket is via soil evaporation or plant transpiration. Thus rooting depth, $z_{r}(\mathrm{~m})$, determines the water potentially available to plants and therefore the effective bucket depth. 


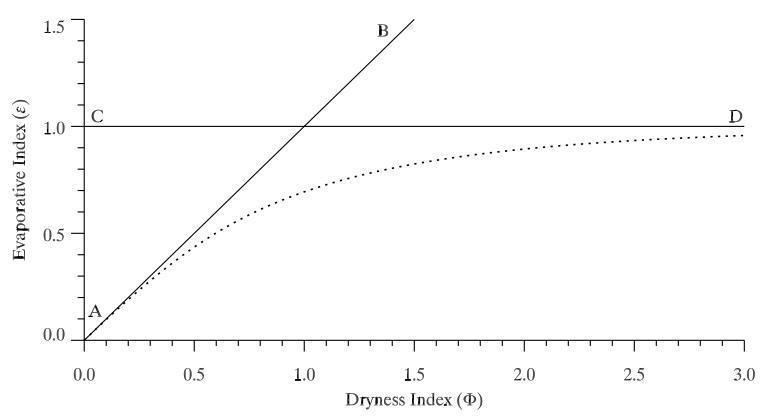

Fig. 1. Budyko's framework and curve. The curve (dotted line), defined by Eq. (12), describes the relationship between the dryness index $\left(\Phi ; \overline{R_{n}} / \lambda \bar{P}\right)$ and the evaporative index $(\varepsilon ; \bar{E} / \bar{P})$. Line A-B defines the energy-limit to evapotranspiration, and line $\mathrm{C}-\mathrm{D}$ defines the water-limit.

Fluxes of both mass and energy are involved in evapotranspiration and this provides a critical link between the water and energy balances. The catchment-wide energy balance is given by:

$\Delta S_{e}=R_{n}-\lambda E-H$

where the change in energy storage $\left(S_{e}\right)$ is the balance between net radiation $\left(R_{n}\right)$ and the fluxes of latent $(\lambda E)$ and sensible $(H)$ heat (all in $\mathrm{J} \mathrm{s}^{-1}$ ) where $\lambda\left(\mathrm{J} \mathrm{kg}^{-1}\right)$ is the latent heat of vaporisation. Note that the sign convention used in Eq. (10) assumes that $\lambda E$ and $H$ are positive away from the surface while $R_{n}$ is positive into the surface. Using the same form as Eq. (9) gives:

$$
\left[S_{e}\right] \frac{\Delta z_{e}}{\tau}+z_{e} \frac{\Delta\left[S_{e}\right]}{\tau}=\frac{\overline{R_{n}}-\lambda \bar{E}-\bar{H}}{A_{c}}
$$

where $z_{e}(\mathrm{~m})$ is the depth to which energy can be stored. Over annual timescales energy storage can usually be omitted from the energy balance.

\subsection{The framework and curve}

Evapotranspiration is limited by the supply of either water or energy. At steady-state, when water is limiting $\left(\overline{R_{n}} / \lambda>\bar{P}\right)$, the maximum possible $\bar{E}$ is $\bar{P}$, at which $\bar{Q}=0$ (Eq. 9). Similarly, the maximum possible $\bar{E}$ when energy is limiting is $\overline{R_{n}} / \lambda$ at which $\bar{H}=0$ (Eq. 11). Evapotranspiration approaches one of these two limits as water or energy, respectively, become increasingly limiting. This framework of mass and energy balances and supply and demand-limited evapotranspiration is the key component of Budyko's work. The type and degree of limitation is determined by the radiative index of dryness $(\Phi)$ which is the ratio of $\overline{R_{n}} / \lambda$ to $\bar{P}$. Values of $\Phi<1$ represent energy-limited environments, and $>1$ waterlimited. Intermediate environments occur where $\Phi \sim 1$.

If all available energy is converted to $\lambda \bar{E}$, then $\bar{E}=\overline{R_{n}} / \lambda$. Budyko considered this to represent "the greatest possible

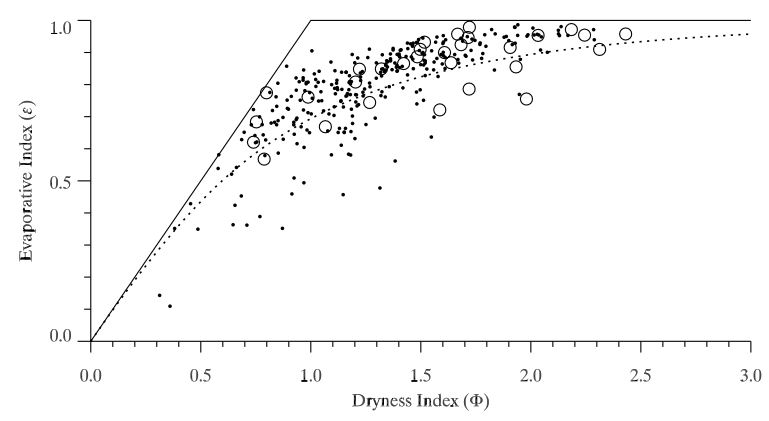

Fig. 2. Plot of mass balance data from 331 Australian catchments showing the deviations of values around the Budyko curve. Large, hollow circles denote the 30 moderate-sized catchments $\left(A_{c} \geq 1000 \mathrm{~km}^{2}\right)$ and small circles denote the remaining 301 smaller catchments $\left(<1000 \mathrm{~km}^{2}\right)$. Data are from Peel et al. (2000) and Raupach et al. (2001) calculated using Eq. (9) with $\tau \geq 8$ years.

value of evaporation under given conditions" (Budyko, 1974, pp. 323). To avoid the need to define the widely used notion of "potential evaporation" (Granger, 1989), subsequent discussion will refer to the available energy simply as $\overline{R_{n}} / \lambda$. This seems like a reasonable simplification as Budyko found that, averaged over a year or longer, $\bar{H}$ is always positive (i.e. provides no net energy input) and that $\overline{R_{n}}$ alone is a good approximation of the available energy.

Catchment-scale annual (or longer) evapotranspiration is usually estimated for gauged catchments by assuming that $\Delta S_{w}$ is 0 and hence $\bar{E}$ is the difference between measured values of $\bar{P}$ and $\bar{Q}$ (Eq. 9). The need for a simple means of estimating $\bar{E}$ from ungauged catchments prompted Budyko to develop the "equation of relationship" that describes the dependency of $\bar{E}$ on the variables $\bar{P}$ and $\overline{R_{n}} / \lambda$ :

$\bar{E}=\left(\frac{\overline{R_{n}} \bar{P}}{\lambda} \tanh \frac{1}{\Phi}(1-\cosh \Phi+\sinh \Phi)\right)^{1 / 2}$

This curvilinear relationship, which built on the works of Schreiber (1904) and Ol'dekop (1911), has become known as the Budyko curve (Fig. 1). Budyko often used the evaporative index $(\varepsilon$; which is $\bar{E} / \bar{P})$ to describe the partitioning of $\bar{P}$ into $\bar{E}$ and $\bar{Q}$. The curve approaches the water and energy limits as values of $\Phi$ become more extreme. $\bar{Q}$ is proportional to the vertical distance between the curve and the water limit and $\bar{H}$ is proportional to the vertical distance between the curve and the energy limit.

Budyko tested this relationship using measured values of $\bar{E}$ from 1200 moderate sized $\left(A_{c}>1000 \mathrm{~km}^{2}\right)$ catchments and found that it explained about $90 \%$ of the variation in observed values. When limited to very large catchments $\left(A_{c}>10000 \mathrm{~km}^{2}\right)$ the relation was even better. This improvement with catchment area was attributed to the (macro-) climate being the principle determinant of $\bar{E}$ over large areas. As $A_{c}$ diminishes (i.e. as catchment size decreases), $\bar{E}$ "may 
vary appreciably under the influence of local conditions of a non-climatic character" such as topography and vegetation (Budyko, 1974, pp. 318 and 330). The availability of energy, as described by $\overline{R_{n}}$, is a micro-climatic variable that is dependent on albedo and surface temperature (Oke, 1987). These, in turn, are affected by surface characteristics such as vegetation cover, slope and aspect which can vary over fine spatial scales (tens to hundreds of metres) depending on landscape complexity. Hence, we take Budyko's statement to mean that, the smaller the catchment area, the more sensitive estimates of $\overline{R_{n}}$ are likely to be to variations in local catchment surface characteristics and vice versa.

\section{Understanding deviations from the Budyko curve}

Budyko did note that systematic deviations occurred between actual and expected values and that it was most pronounced in intermediate climates (Fig. 2) and that these deviations were, in part, related to the seasonal cycles of $P$ and $R_{n} / \lambda$ (Budyko, 1974, pp. 326). When these are in phase, measured values of $\varepsilon$ are slightly higher than expected and, when out of phase, are slightly lower. Budyko did not comment in any detail about the underlying processes.

\subsection{Previous studies}

A number of studies have examined the Budyko curve to find out what causes the deviations (e.g. Eagleson, 1978; Milly, 1994; Choudhury, 1999; Dooge et al., 1999; Koster and Suarez, 1999; Zhang et al., 2001; Sankarasubramanian and Vogel, 2002; Porporato et al., 2004; Potter et al., 2005 ). Many have focused on climatic and geophysical processes alone or have included vegetation but treated it as a constant. Several studies are of particular interest here as they have directly examined the effects of vegetation. Milly (1994) set out to explore reasons why Budyko's curve plots below the energy and water limits and what causes the deviations. Using a stochastic model, Milly found that, when the supplies of energy and water varied seasonally, the phase differences between $R_{n} / \lambda$ and $P$ where important. For example, when the supplies of $R_{n} / \lambda$ and $P$ were seasonal and out of phase there was proportionally less $\bar{E}$ (and more $\bar{Q}$ ) than when they were either non-seasonal or when seasonal and in phase. Soil water storage, which is partly a function of $z_{r}$, provides a buffer against this seasonal climate variability. In times of surplus, water can be stored in situ and is available to vegetation for use at a later time of deficit. Thus, Milly (1994) also found that $\bar{E}$ increases (and $\bar{Q}$ decreases) as potential $S_{w}$ increases. Milly's analysis was grid-based, with a resolution of $0.5^{\circ}\left(A_{c} \sim 2500 \mathrm{~km}^{2}\right.$ at $35^{\circ}$ latitude). When compared to observed values (represented as interpolated surfaces of equivalent resolution) the model explained $88 \%$ and $85 \%$ of the variation in $\bar{Q}$ and $\bar{E}$, respectively. Even though the model allowed for a dynamic $z_{r}$, Milly held this constant in the analyses.

Choudhury (1999) did not directly examined the effects of vegetation yet he did test the effects of spatial scales of analysis $\left(A_{c}\right)$ on predictions of $\bar{E}$ which are significant from a vegetation perspective. Choudhury used Pike's (1964) equation which is numerically similar to Budyko's curve, except that it had an adjustable parameter, $\alpha$ :

$$
\bar{E}=\frac{\bar{P}}{\left(1+\left(\bar{P} \lambda / \overline{R_{n}}\right)^{\alpha}\right)^{1 / \alpha}}
$$

This relationship was tested using observations of $\bar{P}, \overline{R_{n}}$ and $\bar{E}$ derived from mass balances and micro-meteorology at field sites $\left(A_{c} \sim 1 \mathrm{~km}^{2}\right)$, and derived from a biophysical process model (Choudhury and DiGirolamo, 1998) for large basins $\left(A_{c}>1000000 \mathrm{~km}^{2}\right)$. It was found that the dependence of $\bar{E}$ on $\bar{P}$ and $\overline{R_{n}}$ changes with $A_{c}(\alpha=2.6$ for site based observations $\left[\mathrm{r}^{2}=0.99\right]$ and 1.8 for basins $\left.\left[\mathrm{r}^{2}=0.97\right]\right)$. That is, the larger the basin area, the lower the $\alpha$ and the less evapotranspiration for a given $\Phi$ (Fig. 3). Choudhury did not stipulate exactly what physical processes were involved in this scale-dependence in $\alpha$.

Zhang et al. (2001) focused on the role vegetation plays within the Budyko framework, acknowledging that a number of key vegetation characteristics affect evapotranspiration rates. Their aim was to adapt the Budyko framework so that it could be used to quantify the effect of long-term vegetation change on $\bar{E}$. They developed an equation similar to Budyko's and Choudhury's, also with an adjustable parameter, $w$, that they called the "plant available water coefficient":

$\varepsilon=\frac{1+w \Phi}{1+w \Phi+\frac{1}{\Phi}}$

They hypothesised that this parameter should reflect the role of vegetation, particularly $z_{r}$, on $\bar{E}$. In fitting this curve to mass balance data from forested and non-forested catchments, the best-fit values of $w$ were found to be $2.0\left[\mathrm{r}^{2}=0.93\right]$ and $0.5\left[\mathrm{r}^{2}=0.90\right]$, respectively (Fig. 3). Hence, forested catchments (high $w$ ) have higher $\bar{E}$ and lower $\bar{Q}$ for a given $\Phi$ compared to grassed catchments (low $w$ ). Catchment sizes varied between 1 and $600000 \mathrm{~km}^{2}$. Whilst showing that $\bar{E}$ was related to vegetation, no quantitative link was made between these two variables. Zhang et al. (2004) noted that $w$ represents the integrated effect of multiple catchment processes on evapotranspiration, of which vegetation is one, and that a priori estimations of $w$ for a catchment are very difficult. An important point made by these authors (based on the work of Fu, 1981) was that evapotranspiration is most sensitive to variation in $w$ under intermediate climates $(\Phi \sim 1)$.

Building on the work of Milly (1994) and RodriguezIturbe et al. (2001), Porporato et al. (2004) used a simple stochastic model to explore the effect that changes in both $z_{r}$ and the temporal distribution of precipitation have on the 


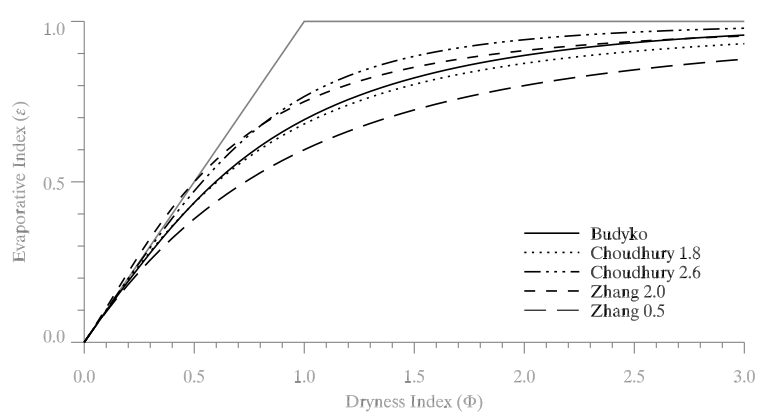

Fig. 3. Comparison of the Budyko curve (Eq. 12) with the curves of Choudhury (1999) (Eq. 13) and Zhang et al. (2001) (Eq. 14). Choudhury 1.8 is calculated using $\alpha=1.8$ and describes $\varepsilon$ from large catchments $\left(A_{c}>1 \times 10^{6} \mathrm{~km}^{2}\right)$. Choudhury 2.6 uses $\alpha=2.6$ and describes field plots $\left(A_{c} \sim 1 \mathrm{~km}^{2}\right)$. Zhang 2.0 and Zhang 0.5 use $w=2.0$ and 0.5 , respectively, and describe $\varepsilon$ from forested and non-forested catchments, respectively.

soil water balance and associated ecological processes. Using the Budyko framework, they showed that $\Delta S_{w}$ has the inverse effect on $\varepsilon$ as a change in average storm depth. That is, an increase in $z_{r}$ shifts the Budyko curve up (increases $\varepsilon$ ) as does a decrease in average storm depth, holding all else constant. These results provide some confirmation of Zhang et al.'s (2001) hypothesis of the relationship between $w$ and $z_{r}$. Porporato et al. (2004) then demonstrated how their reformulation of Budyko could be used to estimate the effect of long-term changes in average storm depth (for a given $\bar{P}$ ) on vegetation productivity, and changes in vegetation on evapotranspiration.

3.2 Interactions between analysis scale, vegetation and Budyko deviations

The only plant functional attribute considered in these previous studies is $z_{r}$. This attribute is generally treated as a constant, except by Porporato et al. (2004) who represent it as a temporally dynamic variable. It is a pragmatic approach to hold $z_{r}$ constant as it is currently a very difficult attribute to measure. Ultimately, it would be extremely useful to integrate vegetation into the framework in a more comprehensive and spatio-temporally dynamic manner as it would enable the Budyko framework be applied to a wider range of ecological and hydrological issues.

The dependence of $\bar{E}$ on the long-term climatic parameters $\bar{P}$ and $\overline{R_{n}} / \lambda$ has been demonstrated by several authors using a variety of equations that represent variations of the Budyko curve. According to Budyko (1974), the numerical similarity of equations describing this relationship is inevitable. The advantage of the Choudhury (1999) and Zhang et al. (2001) equations is computational simplicity and the flexibility afforded by the adjustable parameters. These two adjustable parameters appear also to be functionally similar, possibly

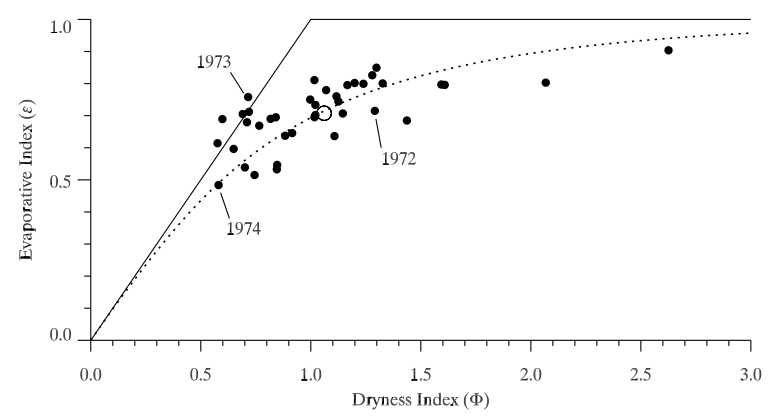

Fig. 4. Inter-annual mass balance data for the Upper Cotter catchment, showing several years with values of $\varepsilon$ above the energy-limit. Values derived with Eq. (9) with $A_{c}=148 \mathrm{~km}^{2}$ and $\tau=1$ year. The progression of $\varepsilon$ and $\Phi$ from 1972 to 1974 is shown to highlight the $\Delta S_{w}$ between a dry year $(1972 ; \bar{P}=780 \mathrm{~mm}, \bar{Q}=220 \mathrm{~mm})$ and a very wet year $(1973 ; \bar{P}=1320 \mathrm{~mm}, \bar{Q}=320 \mathrm{~mm})$ and two very wet years (1973) and $(1974 ; \bar{P}=1460 \mathrm{~mm}, \bar{Q}=750 \mathrm{~mm})$. The hollow circle denotes the long-term ( $\tau=39$ years) value of $\varepsilon$. Data courtesy of Ecowise Services (Australia), Pty. Ltd.

indicating a link between vegetation, $A_{c}$ and variation in $\bar{E}$ and that such a link is most pronounced under intermediate climates.

Vegetation can affect the spatial scales to which the Budyko framework can be applied. Choudhury's (1999) work emphasised the importance of $A_{c}$ in describing the dynamics of $\bar{E}$. As Budyko's curve considers only macroclimatic processes, its reliability is greatest where $A_{c}$ exceeds $1000 \mathrm{~km}^{2}$. This is confirmed by Budyko (1974) and Milly (1994) who, working at large scales, concluded that most variation in $\bar{E}$ could be explained by $\Phi$. Alternatively, over half the catchments used by Zhang et al. (2001) were under $1000 \mathrm{~km}^{2}$ and these authors concluded that vegetation does play an important role in partitioning $\bar{P}$ into $\bar{E}$ and $\bar{Q}$ at these scales. Thus, as $A_{c}$ decreases, the more important it becomes to incorporate the catchment-specific effects of vegetation on the energy and water balances.

Vegetation can also affect the temporal scales appropriate for analysis. Applying the Budyko framework over small time-scales needs to be done carefully in order to maintain steady-state conditions as vegetation dynamics, and particularly net changes in vegetation (e.g. due to harvesting, wildfire and land-use change) can result in large $\Delta S_{w}$ even when $\tau$ is around 1 year. Several examples will illustrate this. Talsma and Gardner (1986) showed that some Eucalyptus species drew more heavily on stored water during the summer of a drought year than the summers of years with average precipitation, using $200 \mathrm{~mm}$ more soil water than average. Another example is given in Fig. 4, which shows evapotranspiration for the Upper Cotter catchment in the Australian Capital Territory $\left(148^{\circ} 50^{\prime}, 35^{\circ} 40^{\prime} \mathrm{S}, 148 \mathrm{~km}^{2}\right)$ calculated using Eq. (9) with $\tau=1$ year. Several years show evapotranspiration values above the energy limit. These years 
had unexpectedly low $\bar{Q}$ given the high $\bar{P}$ and were each preceded by moderately dry years. This catchment contains Sphagnum bogs with large water holding capacities. The observed pattern implies that recharge/discharge of these bogs results in relatively large changes in $S_{w}$. When measured $\bar{P}$ and $\bar{Q}$ are used to estimate $\bar{E}$ using Eq. (9) in a non-steadystate catchment, the estimate of $\bar{E}$ inherently includes $\Delta S_{w}$. Finally, Calder et al. (1997) reported that Eucalyptus plantations established on former croplands exploited substantial stored soil water resulting in unusually high $\bar{E}$ and that $\Delta S_{w}$ could be up to $50 \%$ of $\bar{P}$ for several years after planting (the opposite $\Delta \mathrm{S}_{w}$ would be expected in the years following clearing of the same plantations). These examples demonstrate that vegetation dynamics can result in non-steady-state conditions, especially after net vegetation change, over periods of up to several years. The longer the period needed to establish steady-state conditions, the less useful the approach for catchment and land management applications.

Budyko's curve is based on long-term averages which remove short- to medium-term variability to establish steadystate conditions. Consequently, the reliability of Budyko's curve is diminished if used to address issues of short-term changes in the water balance. This is particularly pertinent to vegetated landscapes as the hydrological role of vegetation can be highly dynamic. It will be of great practical value to apply a Budyko-type framework to inter-annual (and even intra-annual) timeframes and therefore be able to use it to address landscape change.

Besides affecting the spatial and temporal scales to which Budyko can be applied, quantitative incorporation of hydrologically important vegetation characteristics into Budyko's model is also expected to open its scope to more ecologically-oriented applications such as vegetation productivity modelling (e.g. Porporato, 2004), to integrated vegetation and water management and to assessing possible impacts of climate change on catchment processes. A crucial aspect of achieving this is to ensure that the vegetation characteristics have relevance at catchment scales and be readily measured, preferably by some form of remote sensing.

\section{The dynamic role of vegetation in the water balance}

It is well established that vegetation plays an important role in the water balance (e.g. Jones, 1992; Calder, 1993; Arora, 2002; Lee et al., 2005) and that changes in vegetation extent and type are accompanied by changes in catchment evapotranspiration and run-off (Sharma, 1984; Vertessy et al., 2003). This was recently highlighted by Farley et al. (2005) and Jackson et al. (2005) in the context of the hydrological consequences of proposed afforestation for carbon sequestration. Although many plant physiological and structural characteristics affect $\bar{E}$, the three that dominate are: 1) leaf area; 2) photosynthetic rate; and 3) rooting depth (Pierce et al., 1993; Zhang et al., 2001; Arora, 2002; Eamus, 2003). These characteristics have rarely been incorporated into catchmentscale hydrological models (Arora, 2002) most likely because they can be difficult to measure at these scales. Nevertheless, it is important to understand how they each influence $\bar{E}$ in order to understand the nature of, and mechanisms driving, the different water use dynamics of different vegetation types.

\subsection{Three key vegetation attributes}

The first two vegetation characteristics - leaf area and photosynthetic rate - only directly affect the flux components of Eq. (9). Rooting depth, on the other hand, affects both the flux and the steady-state components of the water balance. Focusing on the evaporative flux, $\bar{E}$ can be separated into three fractions: transpiration $\left(\overline{E_{t}}\right)$, evaporation from plant surfaces of intercepted precipitation $\left(\overline{E_{i}}\right)$ and evaporation from soil and other non-vegetated surfaces $\left(\overline{E_{s}}\right.$, all in $\mathrm{kg} \mathrm{s}^{-1}$ ):

$\bar{E}=\overline{E_{t}}+\overline{E_{i}}+\overline{E_{s}}$

The leaf area of canopies is commonly represented using the leaf area index $(L)$ which is the total projected leaf area per unit ground area:

$L=\frac{\text { leaf area }}{\text { ground area }}$

$L$ is an important plant structural attribute that relates to both the energy and water fluxes (Nemani and Running, 1989; Pierce et al., 1993; Hatton and $\mathrm{Wu}, 1995)$. $L$ is related to photosynthesis as it determines the fraction of Photosynthetically Active Radiation absorbed by foliage (fPAR). It alters albedo, and therefore $R_{n}$, as well as surface roughness which influences $\bar{E}$ (Arora, 2002). Of the three vegetation characteristics only $L$ directly affects all three fractions of the evaporative flux. Broadly, $\overline{E_{t}}$ and $\overline{E_{i}}$ are related to $L$ and $\overline{E_{s}}$ is inversely related to $L$. At low values of $L$ common in drier environments ( $\leq 3-5)$ increases in $L$ are accompanied by proportional increases in $\overline{E_{t}}$ and decreases in $\overline{E_{s}}$ (Schulze et al., 1994, Law et al., 2002). As the climate becomes wetter and $L$ increases further, $\overline{E_{t}}$ becomes less responsive to changes in $L$ (Schulze et al., 1994) and the relationship between $\overline{E_{i}}$ and $L$ becomes important, such that $\overline{E_{i}}$ can comprise $40-50 \%$ of $\bar{E}$ in energy-limited environments (Hutley et al., 1997; Barbour et al., 2005). Considering these relations, $L$ bears a general relationship to $\bar{E}$ over most climates.

Leaf area is a highly dynamic vegetation characteristic. It varies with resource availability (Field et al., 1992; Whitehead and Beadle, 2004) being higher where conditions are more favourable for growth. Significant temporal variation occurs due to climate dynamics and the type and age of vegetation. Annual and deciduous species have extreme cyclical variation in $L$ whilst evergreen species have more moderate values with medium-low seasonal variability. $L$ can change inter-annually as a function of vegetation age: young vegetation quickly increases its leaf area which peaks before dropping to a lower and more constant value as it matures (Arora, 
2002). Vegetation age is altered by the frequency of major disturbances (e.g. fires, storms, diseases) and management actions (e.g. destructive harvesting, crop establishment).

Photosynthetic rate $\left(A_{g}\right.$, mol CO$\left._{2} \mathrm{~s}^{-1}\right)$ refers to the net carbon assimilation rate per unit leaf area (Salisbury and Ross, 1992; Larcher, 1995). $A_{g}$ is related, via leaf conductance (Wong et al., 1979), to $E_{t}$ as:

$E_{t}=0.018\left(\frac{A_{g}}{W_{p h}}\right)$

where $W_{p h}$ is the water use efficiency of photosynthesis and is the ratio of the number of moles $\mathrm{CO}_{2}$ gained in photosynthesis to the number of moles $\mathrm{H}_{2} \mathrm{O}$ lost in transpiration, expressed per unit leaf area. In this case, $E_{t}$ is also per unit leaf area. A variety of methods can be used to approximately convert $A_{g}$ to canopy or catchment scales (Norman, 1993) and $W_{p h}$ can be expressed similarly (McVicar et al., 2002) allowing Eq. (17) to be expressed per unit ground area. It can be seen from Eq. (17) that, at a given $W_{p h}$, high $A_{g}$ is accompanied by high rates of transpiration. $A_{g}$ is highly dynamic, varying within and across species and vegetation types, with location and plant age. Highly fertile sites support vegetation with higher $A_{g}$ than resource poor sites (Larcher, 1995; Eamus et al., 2001). There is a general relationship between $A_{g}$, the ratio of leaf area to leaf volume $(\Lambda)$ and leaf longevity (Reich et al., 1997; Roderick et al., 2000). Short-lived, thin leaves (high $\Lambda$ ) typical of annual and deciduous species and the young foliage of evergreens, have high $A_{g}$ compared with long-lived, thick leaves (low $\Lambda$ ) of mature evergreens, all else being equal. Also, $A_{g}$ and $L$ bear a general relationship as both are higher in resource-rich locations and become less as water and/or nutrients become scarce.

Rooting depth $\left(z_{r}\right)$ is an extremely important plant characteristic as it alters the water balance in two ways. Firstly, $z_{r}$ affects the flux components of the water balance (Eq. 9) by determining the soil water potentially available for transpiration. In the absence of roots (vegetation), little buffering of precipitation variability occurs and, considering that evaporation from bare soil rapidly diminishes after precipitation (Ritchie, 1972), the majority of precipitation eventually becomes run-off (Milly, 1994; Porporato et al., 2004). It is worth noting that $z_{r}$ has different affects on $S_{w}$ in different soil types due to differences in $\left[S_{w}\right]$ and that variations in $\left[S_{w}\right]$ can result from changes in vegetation and from management-induced changes in soil structure (Eldridge and Freudenberger, 2005; Craze and Hamilton, 1991). Secondly, $z_{r}$ can affect the steady-state components of the water balance. Roots extend down some proportion of total soil depth. Even though soil depth at a site may be invariant (over typical timescales of interest, e.g. 100 years), $z_{r}$ is not. It can vary inter-annually due to fluctuations in climate (Field et al., 1992), and even seasonally in concert with water table fluctuations (Knight, 1999; Pate and Bell, 1999). Of significance is the potentially rapid changes in $z_{r}$, and therefore in $S_{w}$ (Eq. 9), due to vegetation change. Disturbances such
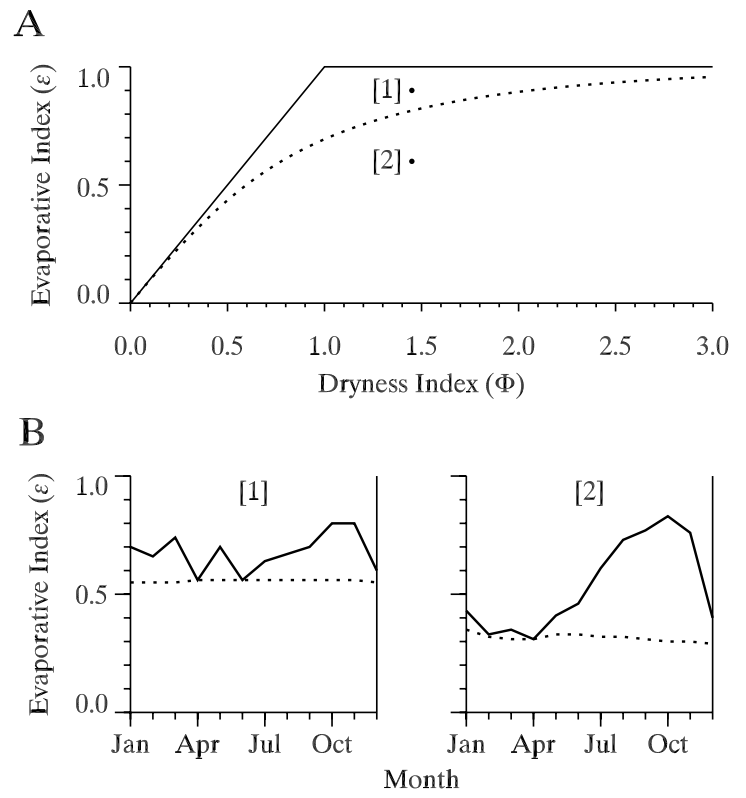

Fig. 5. The effect of seasonal vegetation dynamics on catchment evapotranspiration and run-off. For a given dryness index, catchments with a high proportion of persistent vegetation (e.g. [1]) have greater evapotranspiration fluxes and smaller run-off fluxes (and therefore plot higher on the Budyko curve) than catchments with a high proportion of recurrent vegetation (e.g. [2]).

(A): Indicative values of the evaporative index for catchments [1] and [2], both with $\Phi \sim 1.45$, demonstrating vertical deviations that are possible within the Budyko framework.

(B): Profiles of catchment fPAR showing seasonal vegetation dynamics. Catchment [1] has a higher total fPAR (solid line) and higher proportion of persistent fPAR (dotted line) compared to catchment [2]. Recurrent fPAR is the difference between total and persistent. Catchment [1] supports mostly open Eucalypt forest $\left(149.725^{\circ} \mathrm{E}, 34.070^{\circ} \mathrm{S}\right)$. Catchment [2] supports agricultural pastures with patches of Eucalypt forest $\left(147.369^{\circ} \mathrm{E}, 35.443^{\circ} \mathrm{S}\right)$. Derivations of fPAR and the persistent/recurrent components based on Roderick et al. (1999) using AVHRR Global Area Coverage NDVI data.

as deforestation can almost instantly reduce the effective $z_{r}$ (roots may remain but are generally inactive) whilst regeneration and revegetation can increase it over time. Hence, $z_{r}$ not only affects $\overline{E_{t}}$ but can also alter $\Delta \mathrm{S}_{w}$ and therefore the value of $\tau$ required to achieve steady-state conditions.

\subsection{Seasonal vegetation dynamics}

Budyko (1974) and Milly (1994) both noted that phase differences between the seasonal dynamics of $R_{n} / \lambda$ and $P$ are associated with differences that can occur in $E$ and $Q$ under a given climate. Such differences result in vertical deviations from the Budyko curve where, for a given $\Phi$, a variety of values in $\varepsilon$ can occur (Fig. 5a). As Zhang et al. (2001) 

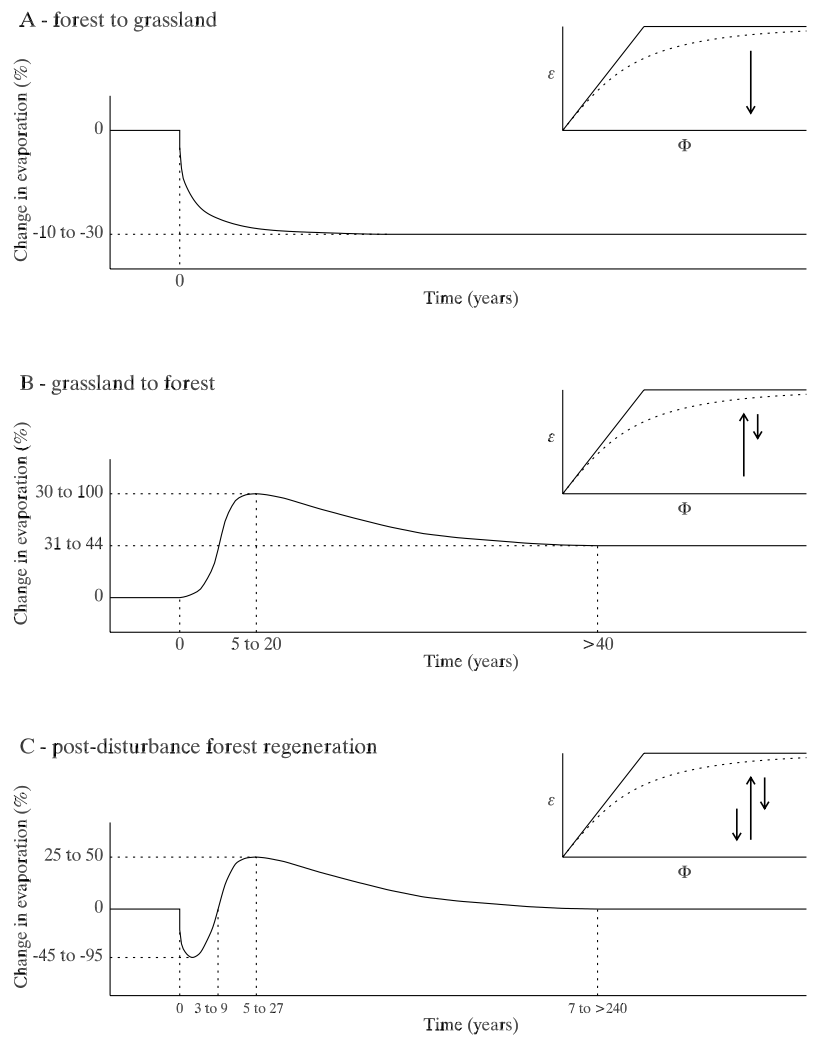

Fig. 6. Changes in catchment evapotranspiration following major vegetation changes.

(A): Conversion of forest to grassland. (B): Conversion of grassland to forest. (C): Forest disturbance and subsequent regeneration. Values given are predominantly based on Eucalypt forests and plantations in water-limited catchments (Langford, 1976; Van Lill et al., 1980; Kuczera, 1987; Pierce et al., 1993; Costa and Foley, 1997; Vertessy, 1998; Cornish and Vertessy, 2001; Gordon et al., 2003; Vertessy et al., 2003; Farley et al., 2005). The timing and magnitude of changes in evapotranspiration vary with annual average precipitation, species and the proportion of catchment undergoing change. Insets indicate vertical changes $(\Delta \varepsilon$ for a given $\Phi)$ in a catchment's location within the Budyko framework associated with each type of vegetation change.

and Porporato et al. (2004) have shown, these vertical deviations also relate to seasonal water use dynamics of different vegetation types. Further, seasonal vegetation dynamics and seasonal climate dynamics are coupled (Berry et al., 2005) - except where the vegetation has been heavily modified such that it would be difficult to ascertain which of the two dynamics are most directly responsible for these deviations.

A useful classification of vegetation which captures these seasonal water use differences is persistent and recurrent functional types. This approach is useful because the functional types can be distinguished in time-series satellite im- agery (DeFries et al., 1995; Roderick et al., 1999; Lu et al., 2003). Persistent vegetation is comprised of species that are active year-round and displays relatively little seasonal variation in canopy structure. This generally encompasses nondeciduous, perennial species. Recurrent vegetation is comprised of species that operate in continuous cycles of activity and dormancy and includes deciduous, annual and ephemeral species. These two types are characterised by differences in the seasonal dynamics of $L$ and $A_{g}$. Also, if deciduous species are uncommon in a catchment, then the useful generalisation can be made that persistents have high and reasonably static $z_{r}$ and recurrents have low $z_{r}$ and this only during the growing season. One consequence of these dynamics is that, for a given climate, $\bar{E}$ from a catchment supporting mostly persistent vegetation should be relatively high and $\bar{Q}$ relatively low compared to that from a catchment with mostly recurrent vegetation (Hatton and Nulsen, 1999; Berry et al., 2005). On the Budyko curve, a persistent catchment is likely to plot above the curve and a recurrent catchment below the curve (Figs. 5a and b), as per Zhang et al. (2001). Describing vegetation simply as annual averages will not fully capture these important differences in $\bar{E}$ and $\bar{Q}$ associated with seasonal vegetation dynamics. Instead, some indication of the relative contributions of recurrent and persistent vegetation types to a catchment's water balance (e.g. Fig. 5b) will most likely explain more of the vertical deviations that occur around the Budyko curve.

\subsection{Annual vegetation dynamics}

Catchments experiencing net vegetation change between years will experience changes in catchment evapotranspiration. The position that such catchments plot on the Budyko curve can change over time even in the absence of changes in the macro-climate. For example, clearing of persistent vegetation means an instant reduction in $z_{r}, A_{g}$ and $L$ and, for a given $\Phi$, is followed by a decrease in $\frac{\delta}{E}$ and an increase in $\bar{Q}$. A change in $S_{w}$ occurs as the soil profile fills in the absence of soil water extraction by deep roots. A new steady-state eventually re-establishes at a lower $\bar{E}$ associated with the replacement vegetation type typically being recurrent (Fig. 6a). This is the typical hydrological impact of clearing for agriculture (Calder, 1993; Pierce et al., 1993; Walker et al., 1993). These changes mean a catchment will progressively plot lower on the Budyko curve. The opposite vegetation change - the replacement of recurrent with persistent vegetation - initially produces a marked increase in $\bar{E}$ and drop in $\bar{Q}$ (Fig. 6b) due to the high $L, A_{g}$ and rapid increases in $z_{r}$ (up to $2.5 \mathrm{~m} / \mathrm{yr}$ (Calder et al., 1997)) associated with young evergreen vegetation. Rapid extraction of $S_{w}$ often occurs. As the vegetation ages, $\bar{E}$ moderates and a new steady-state establishes with higher overall $\bar{E}$ and lower $\bar{Q}$ than that of the original steady-state condition, which eventually locates the catchment higher on the Budyko curve. This is the typical hydrological pattern following 
afforestation (Van Lill et al., 1980; Vertessy et al., 2003; Farley et al., 2005). Both these cycles are observed when persistent vegetation regenerates after disturbance (Fig. 6c) such as after fire (Vertessy, 1998) or after timber harvesting (Cornish and Vertessy, 2001). These examples demonstrate that dramatic vegetation change can disrupt steady-state conditions within catchments and alter the relative proportions of $\bar{Q}$ and $\bar{E}$ for years, and even decades, after large disturbances, ultimately changing a catchment's position within the Budyko framework.

In summary, Sects. 3 and 4 have demonstrated the potentially significant role vegetation plays in the hydrology of catchments. Vegetation dynamics can dictate the spatiotemporal scales appropriate for analyses. This is because the three key vegetation characteristics, $L, A_{g}$ and $z_{r}$, are all spatially and temporarily dynamic. Each can influence the flux components of the water balance whilst $z_{r}$ can also change steady-state conditions. When both $\tau$ and $A_{c}$ are large, it has been found that it is not necessary to explicitly include vegetation in Budyko's framework to achieve reasonable predictions of catchment behaviour. However, as $\tau$ and/or $A_{c}$ become smaller it becomes increasingly important to incorporate both the inter- and intra-annual vegetation dynamics into the framework. One potential way of achieving this may be to utilise remotely sensed vegetation information within the theoretical framework of ecohydrological equilibrium.

\section{Using vegetation information in ecohydrology}

\subsection{Vegetation - the great landscape integrator}

Vegetation directly affects the energy and water balances. However, vegetation grows in response to the combined affect of all conditions that limit growth (Odum, 1993), such as light, temperature, $\mathrm{pH}$, nutrients and disturbances. In environments where the dominant limitation is water, vegetation grows in response to the multiple processes that affect the availability of water (Specht, 1972; Zhang et al., 2004) and may provide a shortcut to quantifying the local, microclimatic factors affecting $\bar{E}$. As Nemani and Running (1989) suggested, vegetation is the great landscape integrator.

\subsection{Ecohydrological equilibrium}

In water-limited environments strong relationships have been found between water availability and mature, perennial vegetation, most particularly vegetation structure (Specht, 1972; Woodward, 1987). Perennial vegetation supports leaf areas that can be predicted from moisture availability and which vary in concert with it. This suggests an ecohydrological equilibrium, or steady-state (Eagleson, 1978, 1982; Nemani and Running, 1989; Pierce et al., 1993; Hatton and Nulsen, 1999), a dynamic condition that fluctuates with micro-climatic variations and only occurs in relatively undisturbed vegetation. Measures of such vegetation are expected to be correlated to the net effect of all processes affecting water availability and may bypass the need to measure each process individually (Zhang et al., 2004). Since $L$ is an aboveground, structural characteristic and is therefore relatively easy to measure compared to $z_{r}$ and $A_{g}$, it is the most useful of the three vegetation characteristics to incorporate into the Budyko model. As $L$ fluctuates according to ecohydrological equilibrium theory, in some circumstances incorporation of $L$ will account for the effects of $z_{r}$, and even changes in $z_{r}$ (Specht, 1972), and may provide a surrogate measure of $z_{r}$. Additionally, $L$ provides a link to land management as $L$ is manipulated by management practices such as planting, harvesting and thinning of vegetation and by modifying site fertility.

5.3 Remotely-sensed measures of Leaf Area Index and the fraction of absorbed Photosynthetically Available Radiation (fPAR)

The easiest means of measuring $L$ across large areas and repeatedly through time is by satellite-based remote sensing. Vegetation has a unique spectral signature (Jones, 1992) which forms the basis of a variety of remotely sensed vegetation indices, including the Simple Ratio (SR) and the more common Normalised Difference Vegetation Index (NDVI). Theory and measurements have shown that SR is linearly related to $L$ whilst NDVI is non-linearly related to $L$ above values of $L$ around 2-4 (Nemani and Running, 1989; McVicar et al., 1996; Carlson, 1997; Lu et al., 2003). The NDVI-L relationship saturates with further increases in $L$. fPAR, on the other hand, is near-linearly related to NDVI (Kumar and Monteith, 1981; Asrar et al., 1984; Lu et al., 2003) and can be related to $A_{g}$ and $E_{t}$ through Monteith's light use efficiency model (Monteith, 1981; Roderick et al., 2001; Berry and Roderick, 2004). Considering the problematic NDVI- $L$ relationship and that fPAR is functionally similar to $L$, from a remote sensing point of view fPAR would be an excellent alternative measure for describing the hydrological role of vegetation.

In applications, integrals of NDVI have often been used (e.g. Prince, 1991; McVicar and Jupp, 1998). Annual NDVI has been found to be linearly related to annual catchment $\bar{E}$ from both an energy-limited environment (Szilagyi, 2000) and a water-limited environment (Mora and Iverson, 1998). For more detailed work, the seasonal dynamics of the fPAR signal can be processed to estimate the persistent and recurrent vegetation types (Fig. 5b) (Roderick et al., 1999; Lu et al., 2003) which can then be used to estimate primary productivity and $\bar{E}$ of the separate types (Berry and Roderick, 2004). It is worth noting that before using fPAR data in applications, it is important to ensure potential sources of signal contamination are accounted for, such as the effects of satellite calibration, atmospheric and cloud interference, and Sun-target-sensor geometry (Gutman, 1999, Kaufman et al. 2000, Tanre et al., 1992). 


\section{Conclusion}

The assumptions inherent in Budyko's hydrological model have been highlighted by explicitly restating the framework to include the temporal $(\tau)$ and spatial $\left(A_{c}\right)$ scales of analysis. The first assumption is that catchments are at steadystate (that is, $\Delta S_{w} \approx 0$ ). To a large degree, this condition depends on $\tau$. The second is that, at large spatial scales $\left(A_{c} \gg 1000 \mathrm{~km}^{2}\right)$, only macro-climatic variables are required to describe catchment water balances. When applied over long timescales and to large catchments, Budyko's curve reliably predicts catchment water balances. However, when applied to small spatio-temporal scales the inherent assumptions can be violated. It is in these circumstances that incorporating vegetation into the framework is expected to enhance the frameworks predictive capacity.

Vegetation is known to play a significant and highly dynamic role in determining catchment evapotranspiration. Vegetation accesses stored soil water, the potential volume of which is determined by $z_{r}$, and evaporates this water into the atmosphere at rates dependent on $L$ and $A_{g}$ amongst other things. The role of vegetation in the water balance is continually changing as $z_{r}, L$ and $A_{g}$ all vary with climatic conditions and with the type and age of vegetation. At small spatial and temporal scales $\left(A_{c} \leq 1000 \mathrm{~km}^{2}\right.$ and $\tau \leq 1-5$ years), which are scales arguably more relevant to management activities than those originally used by Budyko, vegetation becomes an important explanatory variable of catchment hydrological behaviour. This is particularly true for catchments experiencing net vegetation change as this means the relative proportions of $\bar{E}$ and $\bar{Q}$ are shifting and, because of changes in $z_{r}$, steady-state conditions are unlikely to exist in these catchments.

The theory of ecohydrological equilibrium is based on the idea that, in water-limited environments, vegetation is the integrated response to all processes affecting the availability of water. Consequently, incorporation of some key measure of vegetation into Budyko's model is expected to extend the model's ability to describe catchment behaviour to smallscale analyses. $L$ is one such measure as it has been shown to vary with water availability according to ecohydrological equilibrium theory. It is difficult to measure $L$ across large areas and repeatedly through time and so remotely-sensed estimates of fPAR can provide a useful alternative measure of vegetation. We expect that the integration of the temporally dynamic recurrent and persistent components of fPAR into the Budyko framework will extend the framework to be a reliable predictor of $\bar{E}$ and $\bar{Q}$ over small timescales and/or in small catchments, even when those catchments are experiencing significant vegetation change.

As far as we are aware, this proposal has not yet been tested. If such a modified Budyko framework can be developed, its use is expected to extend not only to application at small scales but also to practical applications such as predicting the hydrological effects of vegetation management activ- ities. It is also expected to be a powerful tool for exploring the possible effects of short and long-term climate change on both vegetation and hydrology.

Acknowledgements. This research has been supported by the Research School of Biological Sciences, CSIRO Land and Water and eWater CRC. The ARC Earth System Science Network provided funding for attendance at the Sir Mark Oliphant Conference on Thresholds and Pattern Dynamics in Climate Driven Systems 3-7 July 2005. We particularly thank N. Potter, CSIRO Land and Water, for helpful comments. We also thank the three anonymous reviewers and the editor for their constructive contributions to the manuscript.

Edited by: C. Hinz

\section{References}

Arora, V.: Modeling vegetation as a dynamic component in soilvegetation-atmosphere transfer schemes and hydrological models, Rev. Geophys., 40(2), doi:10.1029/2001RG000103, 2002.

Asrar, G., Fuchs, M., Kanemasu, E. T., and Hatfield, J. L.: Estimating absorbed photosynthetic radiation and leaf-area index from spectral reflectance in wheat, Agronomy J., 76, 300-306, 1984.

Barbour, M. M., Hunt, J. E., Walcroft, A. S., Rogers, G. N. D., McSeveny, T. M., and Whitehead, D.: Components of ecosystem evaporation in a temperate coniferous rainforest, with canopy transpiration scaled using sapwood density, New Phytologist, 165, 549-558, 2005.

Berry, S. L., Farquhar, G. D., and Roderick, M. L.: Co-evolution of climate, soil and vegetation, in: Encyclopaedia of hydrological sciences, edited by: Anderson M., John Wiley And Sons, Indianapolis, 2005.

Berry, S. L. and Roderick, M. L.: Gross primary productivity and transpiration flux of the Australian vegetation from 1788 to 1988 $\mathrm{AD}$ : effects of $\mathrm{CO}_{2}$ and land use change, Global Change Biology, 10, 1884-1898, 2004

Budyko, M. I.: The heat balance of the earth's surface, U.S. Dept. of Commerce, Washington, 1958.

Budyko, M. I.: Climate and life, Academic, New York, 1974.

Calder, I. R.: Hydrologic effects of land-use change, in: Handbook of hydrology, edited by: Maidment, D. R., McGraw Hill, Sydney, 1993.

Calder, I. R., Rosier, P. T. W., Prasanna, K. T., and Parameswarappa, S.: Eucalyptus water use greater than rainfall input-a possible explanation from southern India, Hydrol. Earth Syst. Sci., 1, 249 256, 1997, http://www.hydrol-earth-syst-sci.net/1/249/1997/.

Carlson, T. N., and Ripley, D. A.: On the relation between NDVI, fractional vegetation cover, and leaf area index, Remote Sens. Environ., 62, 241-252, 1997.

Choudhury, B. J.: Evaluation of an empirical equation for annual evaporation using field observations and results from a biophysical model., J. Hydrol., 216, 99-110, 1999.

Choudhury, B. J. and DiGirolamo, N. E.: A biophysical processbased estimate of global land surface evaporation using satellite and ancillary data - I. Model description and comparison with observations, J. Hydrol., 205, 164-185, 1998. 
Cornish, P. M. and Vertessy, R. A.: Forest age-induced changes in evapotranspiration and water yield in a eucalypt forest, J. Hydrol., 242, 43-63, 2001.

Costa, M. H. and Foley, J. A.: Water balance of the Amazon Basin: dependence on vegetation cover and canopy conductance, J. Geophys. Res.-Atmos., 102, 23 973-23 989, 1997.

Craze, B., and Hamilton, G. J.: Soil physical properties, in: Soils - their properties and management, edited by: Charman, P. E. V. and Murphy, B. W., Sydney University Press, South Melbourne, 147-164, 1991.

DeFries, R., Hansen, M., and Townshend, J.: Global discrimination of land cover types from metrics derived from AVHRR pathfinder data, Remote Sens. Environ., 54, 209-222, 1995.

Dooge, J. C. I., Bruen, M., and Parmentier, B.: A simple model for estimating the sensitivity of runoff to long-term changes in precipitation without a change in vegetation, Advances in Water Resources, 23, 153-163, 1999.

Eagleson, P. S.: Climate, soil, and vegetation 4. Expected value of annual evapotranspiration, Water Resour. Res., 14, 731-739, 1978.

Eagleson, P. S.: Ecological optimality in water-limited natural soilvegetation systems, 1 . theory and hypothesis, Water Resour. Res., 18, 325-340, 1982.

Eamus, D.: How does ecosystem water balance affect net primary productivity of woody ecosystems?, Functional Plant Biology, 30, 187-205, 2003.

Eamus, D., Hutley, L. B., and O'Grady, A. P.: Daily and seasonal patterns of carbon and water fluxes above a north Australian savanna, Tree Physiology, 21, 977-988, 2001.

Eldridge, D. J., and Freudenberger, D.: Ecosystem wicks: woodland trees enhance water infiltration in a fragmented agricultural landscape in eastern Australia, Austral Ecology, 30, 336-347, 2005.

Farley, K. A., Jobbagy, E. G., and Jackson, R. B.: Effects of afforestation on water yield: a global synthesis with implications for policy, Global Change Biology, 11, 1565-1576, 2005.

Field, C. B., Chapin, F. S., Matson, P. A., and Mooney, H. A.: Responses of terrestrial ecosystems to the changing atmosphere - a resource-based approach, Ann. Rev. Ecol. Systematics, 23, 201235, 1992.

Fu, B. P.: On the calculation of the evaporation from land surface (in Chinese), Scientia Atmospherica Sinica, 5, 23-31, 1981.

Gordon, L., Dunlop, M., and Foran, B.: Land cover change and water vapour flows: learning from Australia, Philosophical Transactions of the Royal Society of London Series B-Biological Sciences, 358, 1973-1984, 2003.

Granger, R. J.: An examination of the concept of potential evaporation, J. Hydrol., 111, 9-19, 1989.

Gutman, G. G.: On the use of long-term global data of land reflectances and vegetation indices derived from the advanced very high resolution radiometer, J. Geophys. Res.-Atmos., 104, 6241$6255,1999$.

Hatton, T. J. and Nulsen, R. A.: Towards achieving functional ecosystem mimicry with respect to water cycling in southern Australian agriculture, Agroforestry Systems, 45, 203-214, 1999.

Hatton, T. J. and Wu, H. I.: Scaling theory to extrapolate individual tree water-use to stand water-use, Hydrol. Processes, 9, 527-540, 1995.
Hutley, L. B., Doley, D., Yates, D. J., and Boonsaner, A.: Water balance of an Australian subtropical rainforest at altitude: The ecological and physiological significance of intercepted cloud and fog, Aust. J. Botany, 45, 311-329, 1997.

Jackson, R. B., Jobbagy, E. G., Avissar, R., Roy, S. B., Barrett, D. J., Cook, C. W., Farley, K. A., le Maitre, D. C., McCarl, B. A., and Murray, B. C.: Trading water for carbon with biological sequestration, Science, 310, 1944-1947, 2005.

Jones, H. G.: Plants and microclimate, Second edition, Cambridge University Press, Cambridge, 1992.

Kaufmann, R. K., Zhou, L.M., Knyazikhin, Y., Shabanov, N.V., Myneni, R.B., Tucker, C.J.: Effect of orbital drift and sensor changes on the time series of AVHRR vegetation index data, IEEE Transactions on Geoscience and Remote Sensing, 38, 2584-2597, 2000.

Knight, J. H.: Root distributions and water uptake patterns in Eucalypts and other species, in: The ways trees use water, p. 55-85, edited by: Landsberg, J., Rural Industries Research and Development Corporation, publication 99/37, project CSM-4A, Canberra, 1999.

Koster, R. D. and Suarez, M. J.: A simple framework for examining the interannual variability of land surface moisture fluxes, J. Climate, 12, 1911-1917, 1999.

Kuczera, G.: Prediction of water yield reductions following a bushfire in ash-mixed species eucalypt forest, J. Hydrol., 94, 215236, 1987.

Kumar, M. and Monteith, J. L.: Remote sensing of crop growth, Academic press, New York, 1981.

Langford, K. J.: Change in yield of water following a bushfire in a forest of Eucalyptus regnans, J. Hydrol., 29, 87-114, 1976.

Larcher, W.: Physiological plant ecology: ecophysiology and stress physiology of functional groups, Third edition, Springer, Berlin, 1995.

Law, B. E., Falge, E., Gu, L., Baldocchi, D. D., Bakwin, P., Berbigier, P., Davis, K., Dolman, A. J., Falk, M., Fuentes, J. D., Goldstein, A., Granier, A., Grelle, A., Hollinger, D., Janssens, I. A., Jarvis, P., Jensen, N. O., Katul, G., Mahli, Y., Matteucci, G., Meyers, T., Monson, R., Munger, W., Oechel, W., Olson, R., Pilegaard, K., Paw, K. T., Thorgeirsson, H., Valentini, R., Verma, S., Vesala, T., Wilson, K., and Wofsy, S.: Environmental controls over carbon dioxide and water vapor exchange of terrestrial vegetation, Agric. For. Meteorol., 113, 97-120, 2002.

Lee, J. E., Oliveira, R. S., Dawson, T. E., and Fung, I.: Root functioning modifies seasonal climate., Proceedings of the National Academy of Sciences of United States of America, 102, 17 576$17581,2005$.

Lu, H., Raupach, M. R., McVicar, T. R., and Barrett, D. J.: Decomposition of vegetation cover into woody and herbaceous components using AVHRR NDVI time series, Remote Sens. Environ., 86, 1-18, 2003.

McVicar, T. R. and Jupp, D. L. B.: The current and potential operational uses of remote sensing to aid decisions on drought exceptional circumstances in Australia: a review, Agricultural Systems, 57, 399-468, 1998.

McVicar, T. R., Walker, J., Jupp, D. L. B., Pierce, L. L., Byrne, G. T., and Dallwitz, R.: Relating AVHRR vegetation indices to in situ measurements of leaf area index, Technical memorandum 96.5, CSIRO Division of Water Resources, Canberra, 1996.

McVicar, T. R., Zhang, G. L., Bradford, A. S., Wang, H. X., Dawes, 
W. R., Zhang, L., and Li, L. T.: Monitoring regional agricultural water use efficiency for Hebei Province on the North China Plain, Australian J. Agric. Res., 53, 55-76, 2002.

Milly, P. C. D.: Climate, soil water storage, and the average annual water balance, Water Resour. Res., 30, 2143-2156, 1994.

Montaldo, N., Rondena, R., Albertson, J. D., and Mancini, M.: Parsimonious modeling of vegetation dynamics for ecohydrologic studies of water-limited ecosystems, Water Resour. Res., 41, W10416, doi:10.1029/2005WR, 2005.

Monteith, J. L.: Evaporation and surface temperature, Quart. J. Roy. Meteorol. Soc., 107, 1-27, 1981.

Mora, F. and Iverson, L. R.: On the sources of vegetation activity variation, and their relation with water balance in Mexico, Int. J. Remote Sens., 19, 1843-1871, 1998.

Nemani, R. R. and Running, S. W.: Testing a theoretical climate soil leaf-area hydrologic equilibrium of forests using satellite data and ecosystem simulation, Agric. For. Meteorol., 44, 245-260, 1989.

Norman, J. M.: Scaling processes between leaf and canopy levels, in: Scaling physiological processes - leaf to globe, edited by: Ehleringer, J. R. and C. B., Field, Academic, San Diego, 41-76, 1993.

Odum, E. P.: Ecology and our endangered life-support systems, Second edition, Sinaver, Sunderland, 1993.

Oke, T. R.: Boundary layer climates, Second edition, Routledge, London, 1987.

Ol'dekop, E. M.: On evaporation from the surface of river basins., Transactions on meteorological observations., 4, 1911.

Pate, J. S. and Bell, T. L.: Application of the ecosystem mimic concept to the species-rich Banksia woodlands of Western Australia, Agroforestry Systems, 45, 303-341, 1999.

Peel, M. C., Chiew, F. H. S., Western, A. W., and McMahon, T. A.: Extension of unimpaired monthly streamflow data and regionalisation of parameter values to estimate streamflow in ungauged catchments, National Land and Water Resources Audit, Canberra, http://audit.ea.gov.au/anra/water/docs/national/ Streamflow/Streamflow.pdf. 2000.

Pierce, L. L., Walker, J., Dowling, T. I., McVicar, T. R., Hatton, T. J., Running, S. W., and Coughlan, J. C.: Ecohydrological changes in the Murray-Darling Basin .3. A simulation of regional hydrological changes, J. Appl. Ecology, 30, 283-294, 1993.

Pike, J. G.: The estimation of annual run-off from meteorological data in a tropical climate, J. Hydrol., 2, 116-123, 1964.

Porporato, A., Daly, E., and Rodriguez-Iturbe, I.: Soil water balance and ecosystem response to climate change, American Naturalist, 164, 625-632, 2004.

Potter, N. J., Zhang, L., Milly, P. C. D., McMahon, T. A., and Jakeman, A. J.: Effects of rainfall seasonality and soil moisture capacity on mean annual water balance for Australian catchments, Water Resour. Res., 41, W02502, doi:10.1029/2003WR002710, 2005.

Prince, S. D.: A model of regional primary production for use with coarse resolution satellite data, Int. J. Remote Sens., 12, 13131330, 1991.

Raupach, M. R., Kirby, J. M., Barrett, D. J., and Briggs, P. R.: Balances of water, carbon, nitrogen and phosphorus in Australian landscapes: (1) Project description and results, Technical report 40/01, CSIRO Land and Water, Canberra, 2001.

Reich, P. B., Walters, M. B., and Ellsworth, D. S.: From tropics to tundra: global convergence in plant functioning, Proc. National Academy of Sciences of the United States of America, 94, 13730-13 734, 1997.

Ritchie, J. T.: Model for predicting evaporation from a row crop with incomplete cover, Water Resour. Res., 8, 1204-1213, 1972.

Roderick, M. L., Berry, S. L., and Noble, I. R.: A framework for understanding the relationship between environment and vegetation based on the surface area to volume ratio of leaves., Functional Ecology, 14, 423-437, 2000.

Roderick, M. L., Farquhar, G. D., Berry, S. L., and Noble, I. R.: On the direct effect of clouds and atmospheric particles on the productivity and structure of vegetation., Oecologia, 129, 21-30, 2001.

Roderick, M. L., Noble, I. R., and Cridland, S. W.: Estimating woody and herbaceous vegetation cover from time series satellite observations, Global Ecology and Biogeography, 8, 501-508, 1999.

Rodriguez-Iturbe, I. and Porporato, A.: Ecohydrology of watercontrolled ecosystems: soil moisture and plant dynamics, Cambridge University Press, Cambridge, 2004.

Rodriguez-Iturbe, I., Porporato, A., Laio, F., and Ridolfi, L.: Plants in water-controlled ecosystems: active role in hydrologic processes and response to water stress - I. Scope and general outline, Adv. Water Resour., 24, 695-705, 2001.

Salisbury, F. B. and Ross, C. W.: Plant physiology, Fourth edition, Wadsworth, Belmont, 1992.

Sankarasubramanian, A. and Vogel, R. M.: Annual hydroclimatology of the United States, Water Resour. Res., 38, 2002.

Schreiber, P.: Über die Beziehungen zwischen dem Niederschlag und der Wasserführung der Flüsse in Mitteleuropa, Meteorol. Z., 21,1904

Schulze, E.-D., Kelliher, F.M., Korner, C., Lloyd, J. and Leuning, R.: Relationships among maximum stomatal conductance, ecosystem surface conductance, carbon assimilation rate, and plant nutrition: A global ecology scaling exercise, Ann. Rev. Ecol. Syst., 25, 629-660, 1994.

Sharma, M. L.: Evapotranspiration from a Eucalyptus community, Agric. Water Manage., 8, 41-56, 1984.

Specht, R. L.: Water use by perennial evergreen plant communities in Australia and Papua New Guinea, Aust. J. Botany, 20, 273 299, 1972.

Szilagyi, J.: Can a vegetation index derived from remote sensing be indicative of areal transpiration?, Ecological Modelling, 127, 65-79, 2000.

Talsma, T. and Gardner, E. A.: Soil-water extraction by a mixed Eucalypt forest during a drought period, Aust. J. Soil Res., 24, 25-32, 1986.

Tanre, D., Holben, B. N., and Kaufman, Y. J.: Atmospheric correction algorithm for NOAA-AVHRR products - theory and application, IEEE Transactions on Geoscience and Remote Sensing, 30, 231-248, 1992.

Van Lill, W. S., Kruger, F. J., and Van Wyk, D. B.: The effect of afforestation with Eucalyptus-grandis Hill ex Maiden and Pinuspatula Schlecht et Cham on streamflow from experimental catchments at Mokobulaan, Transvaal, J. Hydrol., 48, 107-118, 1980.

Vertessy, R. A.: Predicting water yield from mountain ash forest catchments. Industry report 98/4, Cooperative Research Centre for Catchment Hydrology, 1998.

Vertessy, R. A., Zhang, L., and Dawes, W. R.: Plantations, river 
flows and river salinity, Australian Forestry, 66, 55-61, 2003.

Walker, J., Bullen, F., and Williams, B. G.: Ecohydrological changes in the Murray-Darling Basin .1. The number of trees cleared over 2 centuries, J. Appl. Ecology, 30, 265-273, 1993.

Whitehead, D. and Beadle, C. L.: Physiological regulation of productivity and water use in Eucalyptus: a review, Forest Ecology and Management, 193, 113-140, 2004.

Wong, S. C., Cowan, I. R., and Farquhar, G. D.: Stomatal conductance correlates with photosynthetic capacity, Nature, 282, 424-426, 1979.
Woodward, F. I.: Climate and plant distribution, Cambridge University Press, Cambridge, 1987.

Zhang, L., Dawes, W. R., and Walker, G. R.: Response of mean annual evapotranspiration to vegetation changes at catchment scale, Water Resour. Res., 37, 701-708, 2001.

Zhang, L., Hickel, K., Dawes, W. R., Chiew, F. H. S., Western, A. W., and Briggs, P. R.: A rational function approach for estimating mean annual evapotranspiration, Water Resour. Res., 40, W02502, doi:10.1029/2003WR002710, 2004. 